\title{
Apo-Opsin Exists in Equilibrium Between a Predominant Inactive and a Rare Highly Active State
}

\author{
Shinya Sato, ${ }^{1}$ B Beata Jastrzebska, ${ }^{2}{ }^{\oplus}$ Andreas Engel, ${ }^{2}$ Krzysztof Palczewski, ${ }^{2 \star}$ and ${ }^{\oplus V l a d i m i r}$ J. Kefalov ${ }^{1}$ \\ ${ }^{1}$ Department of Ophthalmology and Visual Sciences, Washington University in St. Louis, St. Louis, Missouri 63110 and ${ }^{2}$ Department of Pharmacology, Case \\ Western Reserve University School of Medicine, Cleveland, Ohio 44106
}

Bleaching adaptation in rod photoreceptors is mediated by apo-opsin, which activates phototransduction with effective activity $10^{5}$ - to $10^{6}$-fold lower than that of photoactivated rhodopsin (meta II). However, the mechanism that produces such low opsin activity is unknown. To address this question, we sought to record single opsin responses in mouse rods. We used mutant mice lacking efficient calcium feedback to boosts rod responses and generated a small fraction of opsin by photobleaching 1\% of rhodopsin. The bleach produced a dramatic increase in the frequency of discrete photoresponse-like events. This activity persisted for hours, was quenched by 11-cis-retinal, and was blocked by uncoupling opsin from phototransduction, all indicating opsin as its source. Opsin-driven discrete activity was also observed in rods containing non-activatable rhodopsin, ruling out transactivation of rhodopsin by opsin. We conclude that bleaching adaptation is mediated by opsin that exists in equilibrium between a predominant inactive and a rare meta II-like state.

Key words: bleaching adaptation; G-protein-coupled receptor; GCAP; opsin; rhodopsin; thermal activation

\section{Significance Statement}

Electrophysiological analysis is used to show that the G-protein-coupled receptor opsin exists in equilibrium between a predominant inactive and a rare highly active state that mediates bleaching adaptation in photoreceptors.

\section{Introduction}

Vision is mediated by activation of the light-sensitive visual pigment in photoreceptor cells. The rod visual pigment rhodopsin is arguably the most studied G-protein-coupled receptor (GPCR) and the rod cascade is the best-understood GPCR signaling cascade (Palczewski, 2006; Ernst et al., 2014). This chain of reactions is triggered when our eyes are exposed to light, activating the visual pigment. The photoactivated visual pigment eventually releases its spent chromophore in the form of all-trans-retinal and decays to apo-opsin (Saari, 2012). Because opsin without chro-

Received Aug. 2, 2018; revised 0ct. 30, 2018; accepted Nov. 4, 2018.

Author contributions: S.S. wrote the first draft of the paper; S.S., B.J., A.E., K.P., and V.J.K. edited the paper; S.S. A.E., K.P., and V.J.K. designed research; S.S. and B.J. performed research; S.S. and B.J. analyzed data; S.S. and V.J.K. wrote the paper.

This work was supported by the National Institutes of Health (Grant EY026675 to V.J.K. and K.P., Grant EY019312 to V.J.K., Grant EY009339 to K.P., Grant EY025214 to B.J., and Grant EY02687 to the Department of Ophthalmology and Visual Sciences, Washington University) and Research to Prevent Blindness. K.P. is the Leopold Chair of Ophthalmology. We thank the staff of the V.K. and K.P. laboratories for comments on the manuscript; Jeannie Chen from the University of Southern California for the Gcaps ${ }^{-1-}$ mice, Michael Redmond from the National Eye Institute for the Rpe $65^{-1-}$ mice, and Janis Lem from Tufts University for the Gnat ${ }^{-1-}$ mice.

The authors declare no competing financial interests.

*K. Palczewski's present address: Gavin Herbert Eye Institute and the Department of Ophthalmology, University of California, Irvine, CA 92697.

Correspondence should be addressed to Dr. Vladimir J. Kefalov, Ophthalmology and Visual Sciences, Washington University School of Medicine, 660 S. Euclid Ave, Box 8096, St. Louis, M0 63110. E-mail: kefalov@wustl.edu.

https://doi.org/10.1523/JNEUROSCl.1980-18.2018

Copyright $\odot 2019$ the authors $\quad 0270-6474 / 19 / 390212-12 \$ 15.00 / 0$ mophore cannot absorb visible light to trigger phototransduction, this process is known as bleaching and the underlying desensitization of the photoreceptors is referred to as bleaching adaptation (Fain et al., 2001). The observed decrease in photoreceptor sensitivity is much greater than would be expected from the decrease in pigment alone, as demonstrated both in the living eye (Campbell and Rushton, 1955) and in isolated rods (Cornwall et al., 1990) and cones (Jones et al., 1993). It is now widely accepted that this excessive desensitization is caused by the final product of photoactivated rhodopsin decay, apo-opsin, which activates the phototransduction cascade even in darkness to produce activity equivalent to that of background light and concurrent reduction in phototransduction gain (Fain et al., 1996).

Biochemical (Okada et al., 1989; Surya et al., 1995; Buczyłko et al., 1996; Jäger et al., 1996; Melia et al., 1997) and physiological (Cornwall and Fain, 1994; Cornwall et al., 1995) studies have shown that opsin exhibits effective catalytic activity of only $10^{-5}$ to $10^{-6}$-fold that of photoactivated rhodopsin (meta II). However, it remains unknown whether opsin has low constitutive activity or exists in equilibrium between distinct inactive and active states. Biochemical studies are not suitable to address these issues on the single-molecule level. Past electrophysiological studies of bleaching adaptation, although informative, have mostly relied on bright bleaches to investigate the physiological effects of free opsin. Because of the high concentration of rho- 
dopsin in photoreceptor outer segments $\left(3-5 \mathrm{~mm} ;>10^{7}\right.$ molecules in a typical photoreceptor; Nickell et al., 2007), even bleaches of $10 \%$ result in the generation of $>10^{6}$ free opsins, again preventing investigation of the catalytic efficiency of individual opsin molecules.

Here, we sought to address these issues by delivering small $(\sim 1 \%)$ bleaches to mouse rod photoreceptors to produce a relatively small number of opsins. Such small bleaches did not cause detectable bleaching adaptation and preserved the high amplification in rods, allowing us to detect signals that would be too small to measure after brighter bleaches. To enhance the signal from individual opsins, we used mice lacking the key calcium feedback on cGMP synthesis regulated by a pair of guanylyl cyclase-activating proteins (GCAP1/2). The lack of this feedback results in several-fold larger single photon responses in mouse rods (Mendez et al., 2001). The combination of using small bleaches and GCAP1/2-deficient $\left(\right.$ Gcaps $\left.^{-/-}\right)$mice ultimately allowed us to observe discrete electrophysiological signals in mouse rods generated by single opsin molecules.

\section{Materials and Methods}

Animals. Mice, both male and female, were kept in a 12:12 light/dark cycle and used at the age of 1-6 months. We obtained Gcaps ${ }^{-1-}$ mice from Dr. Jeannie Chen (University of Southern California), Gnat $1^{-1-}$ mice from Dr. Janis Lem (Tufts University), and Rpe65 $5^{-1-}$ mice from Dr. T. Michael Redmond (National Eye Institute). Gcaps ${ }^{-1-}$ Gnat $^{-1-}$ mice were generated by crossing the existing single knock-out lines. All experimental protocols were in accordance with the National Institutes of Health's Guide for the Care and Use of Laboratory Animals and were approved by the institutional Animal Studies Committee at Washington University.

Retina sample preparation. Mice were dark adapted overnight and killed by $\mathrm{CO}_{2}$ asphyxiation. Under infrared illumination, the eyes were removed and retinas were dissected in Locke's solution containing the following (in mM): $112.5 \mathrm{NaCl}, 3.6 \mathrm{KCl}, 2.4 \mathrm{MgCl}_{2}, 1.2 \mathrm{CaCl}_{2}, 10 \mathrm{HEPES}$, $20 \mathrm{NaHCO}_{3}, 0.02$ EDTA, 3 sodium succinate, 0.5 sodium glutamate, 10 glucose, with $0.1 \%(\mathrm{v} / \mathrm{v})$ MEM vitamins $(\times 100)$ and $0.2 \%(\mathrm{v} / \mathrm{v})$ MEM amino acids $(50 \times)$ in a Petri dish and kept at room temperature in an oxygenated dark box until recordings. When bleached, retinas were transferred into DMEM (D-2902; Sigma-Aldrich) solution supplemented with $15 \mathrm{~mm} \mathrm{NaHCO}, 2 \mathrm{~mm}$ sodium succinate, $0.5 \mathrm{~mm}$ sodium glutamate, $5 \mathrm{~mm} \mathrm{NaCl}$, and $0.1 \%$ (w/v) lipid-free BSA (A6003; SigmaAldrich) (modified from Nymark et al., 2012) and exposed to $500 \mathrm{~nm}$ light (4300 photons $\mu \mathrm{m}^{-2}$ ) for $576 \mathrm{~s}$ to bleach an estimated $1.4 \%$ of rhodopsin. The bleaching fraction was estimated by the relation $F=$ $\exp (-I P t)$ where $F$ is the bleached fraction, $I$ is light intensity $(4300$ photons $\left.\mu \mathrm{m}^{-2} \mathrm{~s}^{-1}\right), P$ is the mouse rod photosensitivity $\left(5.7 \times 10^{-9}\right.$ $\mu \mathrm{m}^{2}$; Woodruff et al., 2004), and $t$ is the bleach time (576 s). After the bleach, the dish was kept in the oxygenated dark box at room temperature until the tissue was used for the recordings. When incubated with retinoid, retina fragments were transferred into retinoid solution and kept for $3 \mathrm{~h}$ in the oxygenated dark box. Retinoid (11-cis-retinal: a generous gift from the National Eye Institute and Dr. Rosalie Crouch; or 11-cis-7-ring-retinal (Kuksa et al., 2002) solution were prepared by diluting a $2 \mu \mathrm{l}$ aliquot of $100 \mathrm{~mm}$ stock solution in ethanol with $2 \mathrm{ml}$ of Locke's solution supplemented with $1 \%(\mathrm{w} / \mathrm{v})$ BSA.

Electrophysiology. Single-cell suction recordings were done as described previously (Wang et al., 2014). The mouse retina was chopped with a razor blade into small pieces, transferred into the recording chamber on a microscope (IX51; Olympus) stage, and perfused with $33-37^{\circ} \mathrm{C}$ Locke's solution equilibrated with $95 \% \mathrm{O}_{2} / 5 \% \mathrm{CO}_{2}$. Retina fragments were visualized by infrared illumination and a camera mounted on the microscope. A single rod outer segment (ROS) was drawn by suction into a microglass pipette filled with electrode solution containing the following (in mM): $140 \mathrm{NaCl}, 3.6 \mathrm{KCl}, 2.4 \mathrm{MgCl}_{2}, 1.2 \mathrm{CaCl}_{2}, 3$ HEPES, 0.02 EDTA, and 10 glucose, pH 7.4 with $\mathrm{NaOH}$, and controlled by a micromanipulator (MP-225; Sutter Instruments). The infrared illumination was turned off during recordings to reduce the instrumental noise and to avoid possible photoactivation of the rod. When recording photoresponses, test flashes generated by a $505 \mathrm{~nm}$ LED (SR-01-E0070; Quadica Developments) were delivered to the recording chamber through a custom-made optical system. The flash intensity and duration were controlled by an LED driver (LDC210; Thorlabs) controlled by a computer with pClamp9 software (Molecular Devices).

The signals from the ROS were amplified with a patch-clamp amplifier (Axopatch 200B; Molecular Devices) and tunable active filter (model 3382; Krohn-Hite), low-pass filtered at $30 \mathrm{~Hz}$ (8-pole bessel, model 3382; Krohn-Hite), digitized at $1 \mathrm{kHz}$ (Digidata 1322A; Molecular Devices), stored, and analyzed on a computer using pClamp9. To facilitate visualization of discrete events, the dark current traces in Figures $1 A, 2 A, 3 A, 4$, $A$ and $C$, and $6 A$ were further digitally low-pass filtered at $10 \mathrm{~Hz}$.

Preparation of opsin membranes. Bovine ROS membranes were prepared from frozen retinas under dim red light as described previously (Papermaster, 1982). Isolated ROS membranes were washed 4 times with hypotonic buffer composed of $5 \mathrm{~mm}$ Bis-tris propane (BTP) and $1 \mathrm{~mm}$ EDTA, $\mathrm{pH} 7.5$, by gentle homogenization and subsequent centrifugation at $25,000 \times \mathrm{g}$ for $30 \mathrm{~min}$ at $4^{\circ} \mathrm{C}$ to remove membrane-associated proteins. The final membrane pellet was suspended in $10 \mathrm{~mm}$ sodium phosphate, $\mathrm{pH} 7.0$, and $50 \mathrm{~mm}$ hydroxylamine to a $3 \mathrm{mg} / \mathrm{ml}$ concentration of rhodopsin, placed on ice, and illuminated with a $150 \mathrm{~W}$ bulb for $30 \mathrm{~min}$. The membranes were then centrifuged at $16,000 \times g$ for 5 min and the pellet was washed 4 times with 10 mm sodium phosphate, $\mathrm{pH} 7.0$, and $2 \%$ BSA followed by four washes with $10 \mathrm{~mm}$ sodium phosphate, $\mathrm{pH} 7.0$, and 2 washes with $20 \mathrm{~mm} \mathrm{BTP,} \mathrm{pH} \mathrm{7.5,} \mathrm{and} 100 \mathrm{~mm} \mathrm{NaCl}$ at $4^{\circ} \mathrm{C}$. These opsin membranes were used either immediately for reconstitution experiments or kept frozen at $-80^{\circ} \mathrm{C}$.

Pigment reconstitution and rhodopsin purification by 1 D 4 immunoaffinity chromatography. Synthesis of 11-cis-7-ring-retinal was done according to published procedures (Kuksa et al., 2002). Opsin membranes were resuspended in $20 \mathrm{~mm} \mathrm{BTP}, \mathrm{pH} 7.5,120 \mathrm{~mm} \mathrm{NaCl}$, and then either 11-cis-retinal or 11-cis-7-ring-retinal was added from a DMSO stock solution to a final concentration of $10 \mu \mathrm{M}$ and incubated overnight at $4^{\circ} \mathrm{C}$ to allow pigment regeneration. On the next day, the membranes were solubilized by addition of dodecyl- $\beta$-D-maltopyranoside (DDM) to a final concentration of $20 \mathrm{~mm}$ and incubated for $1 \mathrm{~h}$ at $4^{\circ} \mathrm{C}$ on a rotating platform. The lysate was centrifuged for $1 \mathrm{~h}$ at $100,000 \times g$ at $4^{\circ} \mathrm{C}$ to remove insoluble material. The cleared supernatant was used to purify regenerated pigments by immunoaffinity chromatography on a customized 1D4 antibody-conjugated $\mathrm{CNBr}$ resin (Salom et al., 2006; Jastrzebska et al., 2013). The antibody ( $6 \mathrm{mg} / \mathrm{ml}$ resin) was coupled to the $\mathrm{CNBr}$-activated Sepharose $4 \mathrm{~B}$ according to the manufacturer's protocol (GE Healthcare Bio-Sciences). An aliquot of $300 \mu \mathrm{l}$ of $6 \mathrm{mg} 1 \mathrm{D} 4 / \mathrm{ml}$ agarose beads were added to the supernatant and incubated for $1 \mathrm{~h}$ at $4^{\circ} \mathrm{C}$ on the rotating platform. The resin was then transferred to a column and washed with $10 \mathrm{ml}$ of buffer consisting of $20 \mathrm{~mm} \mathrm{BTP}, 120 \mathrm{~mm} \mathrm{NaCl}$, and $2 \mathrm{~mm}$ DDM, pH 7.5. Pigments were eluted with the same buffer supplemented with $0.6 \mathrm{mg} / \mathrm{ml}$ of the $1 \mathrm{D} 4$ peptide (amino acid sequence: TETSQVAPA) and their spectra were subsequently measured with a UVvisible spectrophotometer.

$U V$-visible spectroscopy. UV-visible spectra of freshly purified opsin or rod pigment samples were recorded with a UV-visible spectrophotometer (Cary 50; Varian) in the dark or after their illumination at 2000 lux with a Fiber-Light illuminator through a band-pass $(480-520 \mathrm{~nm})$ filter for $5 \mathrm{~min}$. Concentrations of purified samples were quantified using the absorption coefficients $\varepsilon_{280 \mathrm{~nm}}=81,200 \mathrm{M}^{-1} \mathrm{~cm}^{-1}$ (Surya et al., 1995) for opsin and $\varepsilon_{500 \mathrm{~nm}}=40,600 \mathrm{M}^{-1} \mathrm{~cm}^{-1}$ for rhodopsin (Wald and Brown, 1953) and opsin conjugated with 11-cis-7-ring-retinal (11-cis-7ring-rhodopsin).

Transducin activation assay. Transducin was purified after extraction from ROS membranes isolated from 200 dark-adapted bovine retinas as described previously (Goc et al., 2008; Jastrzebska, 2015). Activation properties of WT rhodopsin or 11-cis-7-ring-rhodopsin were tested in the Trp fluorescence transducin activation assay (Kuksa et al., 2002). Transducin was mixed with rhodopsin or 11-cis-7-ring-rhodopsin samples at a 10:1 ratio, with transducin at $250 \mathrm{~nm}$ and pigment at $25 \mathrm{~nm}$ concentrations in buffer composed of $20 \mathrm{~mm} \mathrm{BTP,} \mathrm{pH} \mathrm{7.0,} 120 \mathrm{~mm} \mathrm{NaCl}$, 
$2 \mathrm{~mm} \mathrm{MgCl}_{2}$, and $1 \mathrm{~mm}$ DDM. The samples were exposed to light through a band-pass wavelength filter (480-520 nm), reaching 2000 lux intensity for $30 \mathrm{~s}$ with a Fiber-Light illuminator, followed by a $5 \mathrm{~min}$ incubation with continuous low-speed stirring. Transducin activation was recorded for $25 \mathrm{~min}$ as the intrinsic fluorescence increase from its $\alpha$-subunit due to guanylyl nucleotide exchange upon addition of $5 \mu \mathrm{M}$ GTP $\gamma S$ with a PerkinElmer LS 55 Luminescence Spectrophotometer. Excitation and emission wavelengths were used at 300 and $345 \mathrm{~nm}$, respectively (Fahmy and Sakmar, 1993; Farrens et al., 1996; Heck and Hofmann, 2001). A pseudo-first order kinetic rate $(k)$ of $\mathrm{G}_{\mathrm{t}}$ activation was derived from the function: $A(t)=A_{\max }\left(1-\exp ^{-\mathrm{kt}}\right)$, where $A_{\max }$ is the maximal $G_{\alpha \mathrm{t}}$ fluorescence change and $A(t)$ is the relative fluorescence change at time $t$. No signals were detected in control experiments without transducin. All samples were measured in triplicate.

Statistical analysis. Electrophysiology data analysis, including statistical analysis, fitting, and figure preparation, was performed with Origin 9 software (OriginLab). All data, where applicable, are presented as mean \pm SEM. The statistical significance of difference between parameters calculated from the mutant and control samples was tested with a two-tailed unpaired Student's $t$ test or with one-way ANOVA $(p<0.05)$.

\section{Results}

Small bleaches induce photoresponselike discrete events by apo-opsin in Gcaps $^{-1-}$ rods

The activation of a single rhodopsin molecule can be observed as a single-photon response by electrophysiological recordings from individual rods (Baylor et al., 1979; Yau et al., 1979). However, electrophysiological responses from single apo-opsin have not been measured or observed, presumably due to the small activity of individual opsins. To investigate this and to resolve the expected small responses of individual opsins, we chose to study opsin activity using GCAP1/2-deficient $\left(\mathrm{Gcaps}^{-1-}\right)$ rods. The deletion of these two calcium-dependent guanylyl cyclase modulators boosts the amplitude of the single-photon response approximately fivefold in mouse rods (Mendez et al., 2001). This makes small signals obtained by single-cell recordings easier to detect in $\mathrm{Gcaps}^{-I-}$ rods than in WT rods.

We introduced apo-opsin molecules by bleaching a small fraction of the total rhodopsin with $500 \mathrm{~nm}$ light before the recordings. In the case of $\mathrm{Gcaps}^{-1-}$ rods, we found that bleaches larger than $10 \%$ reduced the phototransduction gain to the point where single photon responses could no longer be observed. Therefore, we restricted our studies to bleaching only $\sim 1 \%$ of rhodopsin. Results from even smaller bleaches proved difficult to interpret, possibly due to pigment regeneration with residual amounts of 11-cis-retinal in the bleached rods (Lyubarsky and Pugh, 2007).

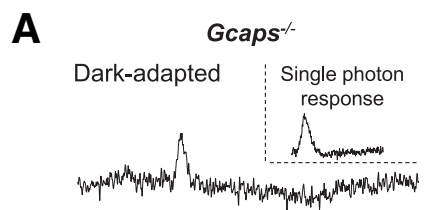

Bleached, $2 \mathrm{~h}$

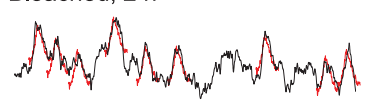

Bleached, $12 \mathrm{~h}$

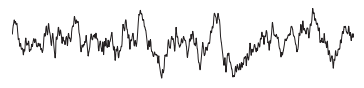

Dark-adapted +dim background light

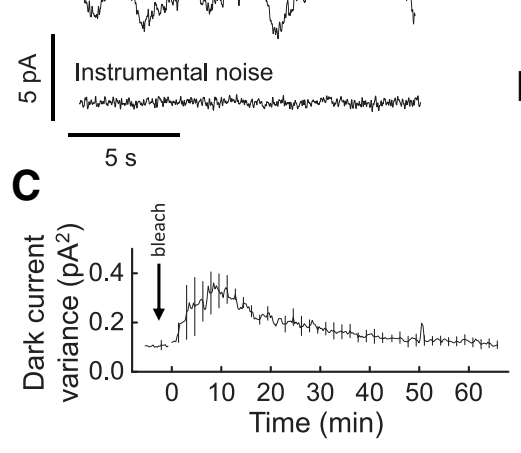

E

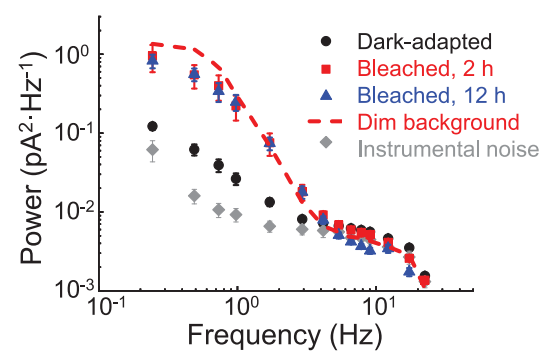

B

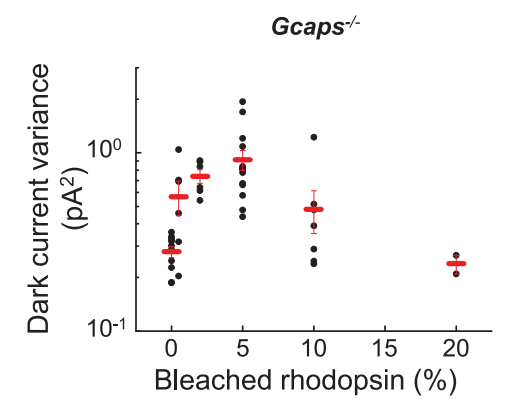

D

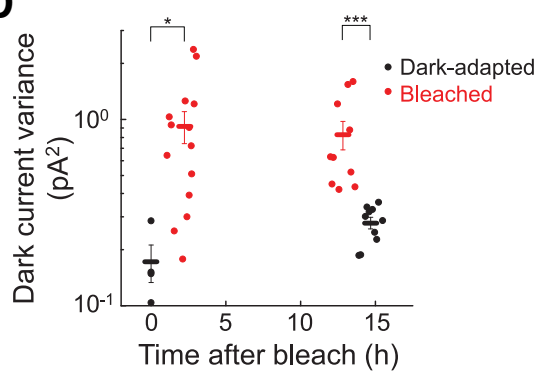

$\mathbf{F}$

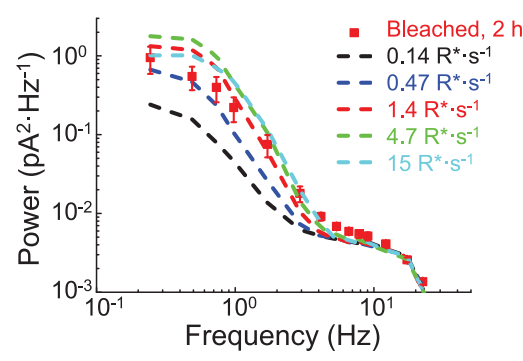

Figure 1. Bleach-induced discrete transduction activity in single $\mathrm{Gcaps}^{-1-}$ rods in darkness. $\boldsymbol{A}$, Current recorded in darkness from a dark-adapted unbleached rod (dark-adapted), a rod after 1.4\% rhodopsin bleach followed by $2 \mathrm{~h}$ incubation in darkness (bleached, $2 \mathrm{~h}$ ), and a rod $12 \mathrm{~h}$ after a 1.4\% rhodopsin bleach (bleached, $12 \mathrm{~h}$ ). For comparison, the fourth trace shows the current recorded from an unbleached rod in $500 \mathrm{~nm}$ dim background light producing an estimated $1.4 \mathrm{R}^{*} \mathrm{~s}^{-1}$ (dark-adapted + dim background light). The bottom trace (instrumental noise) shows the rod instrumental noise recorded in bright background light. To illustrate the similarity between the discrete events in bleached rods and the single-photon response, individual events in the bleached, $2 \mathrm{~h}$ trace have been overlapped with the corresponding single photon response (drawn in red). Inset, Single photon response waveform estimated from dim flash responses of a dark-adapted rod. $\boldsymbol{B}$, Total dark current variance of rods with increasing fractions of bleached rhodopsin (black circles). Red bars show mean \pm SEM. C, Averaged rod dark current variance recorded over the course of $65 \mathrm{~min}$ after a $1.4 \%$ bleach $(n=3)$. $\boldsymbol{D}$, Total dark current variance of dark-adapted rods (black circles) or rods $2 \mathrm{~h}$ (left) or $12 \mathrm{~h}$ (right) after $1.4 \%$ rhodopsin bleach (red circles). Bars show mean \pm SEM of each group of data points. ${ }^{*} p<0.05$, ${ }^{* * *} p<0.005$ by two-tailed unpaired $t$ test. $\boldsymbol{E}$, Averaged power spectra of the dark current recorded from rods that were darkadapted (dark-adapted, black circles, $\mathrm{n}=10$ ), after a 1.4\% rhodopsin bleach and incubation in darkness for $2 \mathrm{~h}$ (bleached, $2 \mathrm{~h}$, red squares, $n=8$ ) or for $12 \mathrm{~h}$ (bleached, $12 \mathrm{~h}$, blue triangles, $\mathrm{n}=9$ ), or in bright background light (instrumental noise, $\mathrm{n}=6$ ). Dashed line is the power spectrum from unbleached rods under dim background light $(n=3)$ as in $\boldsymbol{A}$. $\boldsymbol{F}$, Comparison of the power spectrum of bleached rods (red squares) with the power spectra of unbleached rods in a series of backgrounds ranging from 0.14 to $15 \mathrm{R}^{*} \mathrm{~s}^{-1}$. Plots are shown as mean \pm SEM.

The light-independent intrinsic transduction activity in single rods was recorded by suction-electrode recordings. Recordings from unbleached dark-adapted control Gcaps ${ }^{-1-}$ rods in complete darkness revealed a quiet baseline, with an occasional spontaneous photoresponse-like event presumably caused by spontaneous thermal activation of rhodopsin (Fig. 1A, dark-adapted trace). Such spontaneous events had the shape and amplitude of singlephoton responses (Fig. 1A, inset) and were observed only sporad- 
ically, consistent with the previously estimated rate of $\sim 1 /$ min (Mendez et al., 2001). To introduce a small fraction of opsin in the rods, isolated Gcaps ${ }^{-1-}$ retinas were exposed to $500 \mathrm{~nm}$ light to bleach an estimated $\sim 1.4 \%$ of rhodopsin. After the bleach, $\mathrm{Gcaps}^{-/-}$rods were incubated in darkness for $2 \mathrm{~h}$ to allow for the decay of photoactivated rhodopsin to apo-opsin (Nymark et al., 2012). Surprisingly, bleaching such a very small fraction of rhodopsin in the Gcaps ${ }^{-1-}$ rods resulted in a dark baseline with frequent discrete events (Fig. $1 \mathrm{~A}$, bleached, $2 \mathrm{~h}$ trace). This activity could be suppressed by saturating the rod transduction cascade with bright light (Fig. $1 A$, instrumental noise trace). The great majority of these events could be fit well by the corresponding single-photon response (Fig. $1 A$, red traces) measured independently from dim flash analysis. The remaining bumps in the trace where such a match was not possible appeared to reflect several overlapping events masking each other. Increasing the bleached fraction of rhodopsin initially led to higher activity in darkness as quantified by the total variance in the dark current (Fig. $1 B$ ). However, for bleaches $>5 \%$, the level of bleachinduced activity began to decline due to the reduction in the phototransduction gain caused by bleaching adaptation. This behavior is reminiscent of the effect of background light of increasing intensity on the variance of the dark current: dim backgrounds produce notable increase of the discrete bumps caused by single-photon activations. However, as the background light becomes brighter, the frequency of these discrete events increases, eventually causing desensitization and subsequent reduction in current variance (Baylor et al., 1979; Vu et al., 1997; Jones, 1998).

Consistent with the visible increase in transduction activity of rods after the $1.4 \%$ bleach and $2 \mathrm{~h}$ incubation in darkness, the total variance in their dark current also increased significantly (Fig. 1D, left). Further quantitative analysis demonstrated that their power spectrum was also boosted substantially following the bleach (Fig. 1E). The additional power in the spectrum of bleached rods was dominated by low-frequency components $(0.2$ to $2 \mathrm{~Hz}$ ), with a shape comparable to that of the power spectrum of the light-induced single-photon response (see below). In contrast, the higher-frequency components of the power spectrum were not affected by the bleach. The activity of the bleached Gcaps $^{-1-}$ rods was comparable to that of unbleached darkadapted $\mathrm{Gcaps}^{-1-}$ rods in the presence of dim background light, activating an estimated $1.4 \mathrm{R}^{*} \mathrm{~s}^{-1}$ (Fig. $1 A$, dark-adapted + dim background light trace), suggesting that they both originate from a small number of discrete photoresponse-like events. The increase in photoactivation by the background also resulted in a power spectrum comparable to that of the bleached rods (Fig. $1 E, F)$.

The small bleach did not cause detectable adaptation, leaving sensitivity comparable $\left(1.5 \pm 0.3 \mathrm{pA}\right.$ photon $\left.{ }^{-1} \mu \mathrm{m}^{2}\right)$ in darkadapted rods $(n=14)$ and bleached rods $(n=8)$. Furthermore, the dark current was also not affected and was comparable, $13.7 \pm 1.0 \mathrm{pA}(n=14)$ for dark-adapted and $12.4 \pm 1.6 \mathrm{pA}(n=$ 8) for bleached GCAPs $^{-1-}$ rods. Therefore, the state of the phototransduction cascade was not affected by the light exposure, leaving instrumental and cellular noise comparable. This allowed us to compare the increase in the power spectrum of the bleached rods caused by free opsin directly with that of the rods in background light. Our results show that introducing a relatively small $\sim 1 \%$ fraction ( $\sim 7 \times 10^{5}$ molecules) (Lyubarsky et al., 2004) of apo-opsin produced activation of the phototransduction cascade comparable to that of photoactivating $\sim 1$ rhodopsin molecules/s by background light. This finding is consistent with previous estimates of the low effective activity of opsin compared with meta II. However, unlike in previous studies using large bleaches, introducing only a small fraction of opsin in our recordings gave rise to frequent, discrete photoresponse-like events in darkness.

The most likely explanation for this surprising increase in the frequency of photoresponse-like events in mouse rods following a small bleach is that they were generated by the final product of the photoreactions of rhodopsin, namely apo-opsin. However, an alternative, trivial explanation of our results is that substantial meta II was still present in the bleached ccaps $^{-1-}$ rods even at $2 \mathrm{~h}$ after the bleach. The time constant of meta III decay is $\sim 15 \mathrm{~min}$ (Imai et al., 2007; Nymark et al., 2012) and meta III can revert to meta II (Zimmermann et al., 2004; Sommer et al., 2011) to produce photon-like events (Leibrock et al., 1994; Leibrock and Lamb, 1997). Indeed, consistent with the latter two studies, we did observe an initial large increase of the transduction activity after a bleach, followed by gradual quenching as the photoproducts of rhodopsin gradually decayed to opsin (Fig. 1C). Therefore, our results confirm and extend the findings of Leibrock and Lamb (1997) showing that metarhodopsin intermediates can produce photoresponse-like events in the first few minutes after a small bleach in mouse rods. However, as shown in Figure 1, $A$ and $D$, left, and $E$, the transduction activity even $2 \mathrm{~h}$ after bleach remained higher than that of unbleached rods. To investigate further the possible involvement of meta II and meta III in the generation of the discrete events in bleached rods, we measured the activity from Gcaps $^{-/-}$rods incubated in darkness for $12 \mathrm{~h}$ after the bleach. If metaproducts of rhodopsin were the major source of the activity, then the frequency of photon-like events would be expected to decline after their decay during this longer incubation, eventually returning to its prebleach level. However, the activity (Fig. 1A, bleached, $12 \mathrm{~h}$ trace), dark current variance (Fig. 1D, right), and power spectrum (Fig. 1E) of bleached Gcaps $^{-1-}$ rods were comparable for the 2 and $12 \mathrm{~h}$ postbleach recovery periods. These results demonstrate that, although intermediate metaproducts of rhodopsin contribute to the bleachinduced activity in the first few postbleach minutes, they are not the source of the observed activity at steady state in bleached mouse rods. Therefore, we conclude that the photoresponse-like events in bleached Gcaps $^{-/-}$rods at steady state are generated by opsin.

\section{There are no photoresponse-like discrete events in bleached Gcaps $^{-/-}$rods lacking transducin}

To investigate the source of the photoresponse-like events in bleached Gcaps ${ }^{-1-}$ rods, we crossed Gcaps ${ }^{-1-}$ mice with mice that lacked the $\alpha$-subunit of G-protein transducin $\left(\right.$ Gnat $\left.1^{-/-}\right)$. The deletion of transducin $\alpha$ in mouse rods blocks rod phototransduction by uncoupling rhodopsin photoactivation from the activation of the effector enzyme, phosphodiesterase. Importantly, rods in Gnat $^{-1-}$ mice retain normal morphology (Calvert et al., 2000). This allowed us to use Gnat $1^{-1-}$ rods to evaluate the transduction activity originating downstream of opsin and transducin, as well as the instrumental noise. As expected, no spontaneous events with the shape and amplitude of singlephoton responses were observed in ccaps $^{-1-}$ Gnat $^{-1-}$ rods (Fig. 2A, dark-adapted trace). A subsequent bleach failed to produce a visible increase in transduction activity in Gcaps ${ }^{-1-}$ Gnat $1^{-1-}$ rods, as demonstrated by the comparable prebleach and postbleach dark current (Fig. $2 A$, bleached, $2 \mathrm{~h}$ trace). Similarly, the power spectra of dark-adapted and bleached Gcaps ${ }^{-1-}$ Gnat $1^{-/-}$rods were comparable (Fig. 2B) and dramatically lower than the power spectrum of bleached ccaps $^{-1-}$ rods (Fig. 1D). 
These results demonstrate that the increased activity in bleached Gcaps ${ }^{-1-}$ rods does not originate from downstream phototransduction components or from instrumental noise. Consistent with this notion, background light also had no effect on the level of activity in Gcaps ${ }^{-1-}$ Gnat $1^{-1-}$ rods (Fig. $2 A$, bottom trace, $B$ ).

To isolate the activity produced by apo-opsin in the bleached Gcaps ${ }^{-1-}$ rods, we next subtracted the power spectrum of Gcaps $^{-1-}$ Gnat $^{-1-}$ rods from that of bleached Gcaps ${ }^{-1-}$ rods. This difference power spectrum was well fitted with the power spectrum of the single-photon response recorded from Gcaps $^{-1-}$ rods (Fig. 2C). Assuming that transducin itself does not generate detectable activity (Rieke and Baylor, 1996), this result suggests that the frequency composition of the discrete events produced by apoopsin in the bleached Gcaps ${ }^{-1-}$ rods is comparable to that of the single photon response produced by photoactivated rhodopsin (meta II). The simplest explanation for this similarity is that the discrete noise in bleached rods is driven by events with a waveform similar to that of the single photon response. Comparison of the amplitudes of the power spectra of bleached rods and the single-photon response revealed that the increased activity of Gcaps $^{-1-}$ rods after $1.4 \%$ bleach is equivalent to that produced by the photoactivation of $\sim 0.6$ rhodopsin molecules/s, a value consistent with our background light analysis above (Fig. 1E).

\section{Treatment with 11-cis-retinal quenches bleach-induced} activity in Gcaps $^{-1-}$ rods

To further confirm that opsin is the source of the photoresponselike discrete events observed in bleached rods, some of the bleached Gcaps ${ }^{-1-}$ rods were incubated with $100 \mu \mathrm{M}$ exogenous 11-cis-retinal to convert the apo-opsin produced by the bleach back into rhodopsin by regeneration. In control experiments, the abundance of discrete photoresponse-like events in bleached $\mathrm{Gcaps}^{-1-}$ rods was not affected by vehicle treatment (Fig. 3A, bleached +vehicle). However, the number of photoresponse-like events in bleached rods was dramatically reduced after the incubation with 11-cis-retinal (Fig. 3A, bleached +11-cis-retinal). Similarly, the power spectrum of bleached Gcaps $^{-1-}$ rods treated with 11-cis-retinal was significantly suppressed compared with that of vehicle-treated controls (Fig. 3B). Treatment of bleached Gcaps ${ }^{-1-}$ rods with chromophore reduced their power spectrum to a level comparable to that of dark-adapted rods (Fig. $3 B$ ). Therefore, regeneration of the bleached opsin back to rhodopsin largely reversed the increase in discrete transduction activity produced by the bleach. This result further supports the notion that the discrete photoresponse-like events observed in bleached Gcaps $^{-1-}$ rods are generated by free opsin.
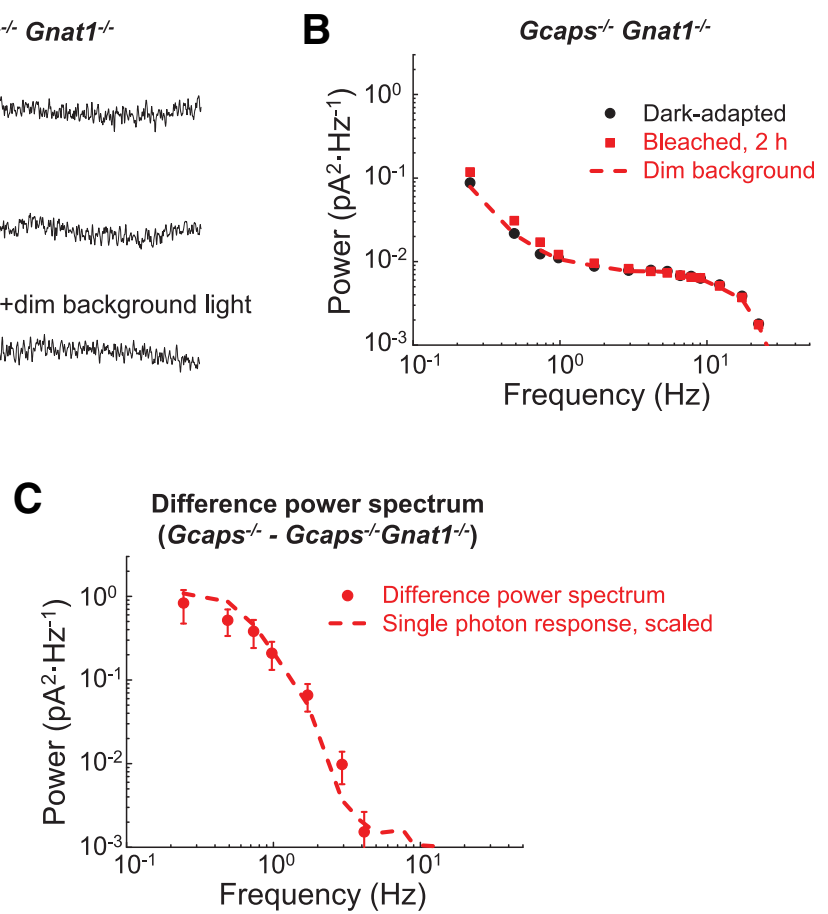

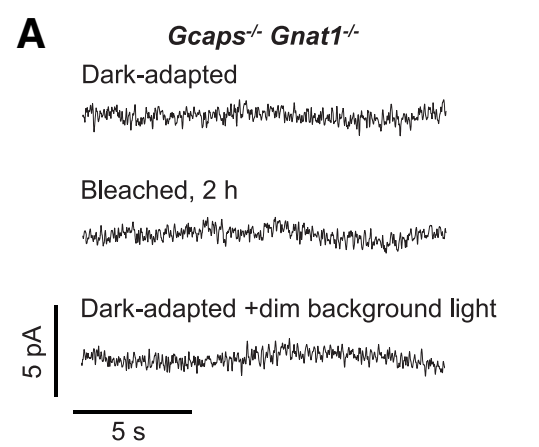

Figure 2. Lack of bleach-induced transduction activity in Gcaps ${ }^{-1-}$ Gnat $^{-1-}$ rods. $A$, Current recorded in darkness from a

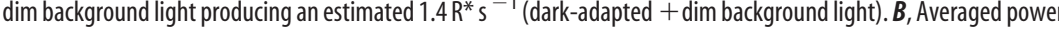
hodopsin bleach and incubation in darkness for $2 \mathrm{~h}$ (bleached, $2 \mathrm{~h}$, red squares, $\mathrm{n}=10$ ). Dashed line is the power spectrum from unbleached rods under dim background light $(n=3)$ as in $A$. C, Difference in the power spectrum between bleached Gcaps ${ }^{-1-}$ and Gcaps $^{-1-}$ Gnat $^{-1-}$ rods (red circles). Data were fitted with scaled power spectrum of single photon response (red dash line) with a scaling factor of 2.35. Plots in $\boldsymbol{B}$ and $\boldsymbol{C}$ are shown as mean \pm SEM.

\section{Small bleaches induce photoresponse-like discrete events in WT rods}

Our results above demonstrate that bleaching a small fraction of rhodopsin in Gcaps $^{-1-}$ rods results in a dramatic increase in the frequency of photoresponse-like events in darkness. We next sought to confirm that the same phenomenon occurs in WT rods. The WT C57BL/6 mouse retina was subjected to the same small bleach and rod activity was measured with the same methods as the $\mathrm{Gcaps}^{-1-}$ rods above. Individual single photon responses of WT rods are relatively small ( $\sim 0.5 \mathrm{pA}$; Mendez et al., 2000) and comparable in size to the $\sim 1 \mathrm{pA}$ instrumental noise level. Therefore, in contrast to the case of Gcaps $^{-1-}$ rods, the visible difference in activity between bleached and unbleached WT rods was expected to be very small. Indeed, we obtained seemingly identical traces from dark-adapted and bleached WT rods (Fig. 4A, dark-adapted vs bleached traces). Similarly, exposing WT rods to dim background that substantially increased the activity in Gcaps $^{-1-}$ rods produced no visible increase in their baseline activity (Fig. 4A, dark-adapted + dim background trace). However, examination of the power spectra of WT rods revealed an increase in their low-frequency activity induced by both the bleach and the dim background light (Fig. 4B). This result is similar to our findings in $\mathrm{Gcaps}^{-1-}$ rods above and indicates that introducing a small fraction of opsin in WT rods results in frequent photoresponse-like events comparable to these produced by dim background light. Importantly, the small bleach did not cause measurable change in the sensitivity of dark-adapted rods $\left(0.28 \pm 0.03 \mathrm{pA}\right.$ photon $\left.{ }^{-1} \mu \mathrm{m}^{2}, n=14\right)$ versus bleached rods $\left(0.31 \pm 0.03\right.$ pA photon $\left.{ }^{-1} \mu \mathrm{m}^{2}, n=16\right)$ or of their dark current 
A

\section{Gcaps $^{-/-}$}

Bleached +vehicle

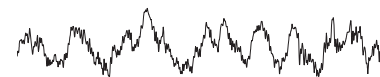

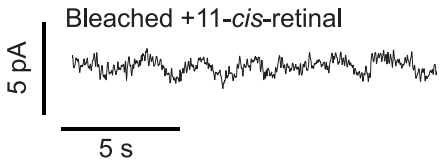

B

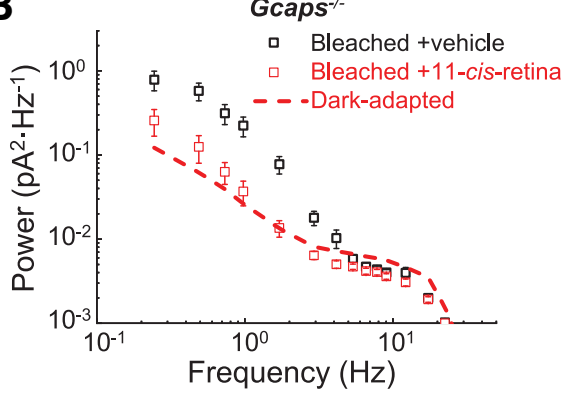

Figure 3. Quenching of transduction activity in bleached $\mathrm{Gcaps}^{-1-}$ rods after pigment regeneration. $\boldsymbol{A}$, Current recorded in darkness from a rod after $1.4 \%$ rhodopsin bleach and $3 \mathrm{~h}$ incubation with vehicle for control (bleached + vehicle) or with $100 \mu \mathrm{m}$ exogenous 11-cis-retinal (bleached +11-cis-retinal). B, Averaged power spectra of the dark current recorded from rods after 1.4\% rhodopsin bleach and incubation in darkness for $3 \mathrm{~h}$ with vehicle (bleached + vehicle, open black squares, $n=6$ ) or with $100 \mu \mathrm{m}$ exogenous 11-cis-retinal (bleached +11 -cis-retinal, open red squares, $n=6$ ). The red dashed line represents the power spectrum of dark-adapted $\mathrm{Gcaps}^{-1-}$ rods from Figure $1 D$ for comparison. Plots are shown as mean \pm SEM.

A Dark-adapted

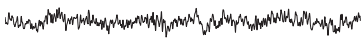

Bleached

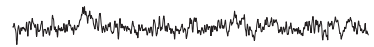

Dark-adapted +dim background light

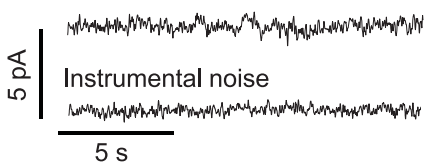

C Gnat1\%

Dark-adapted

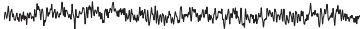

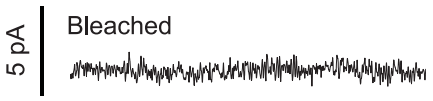

$5 \mathrm{~s}$
B

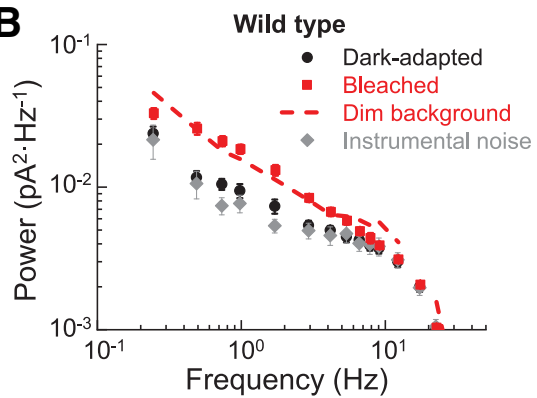

D

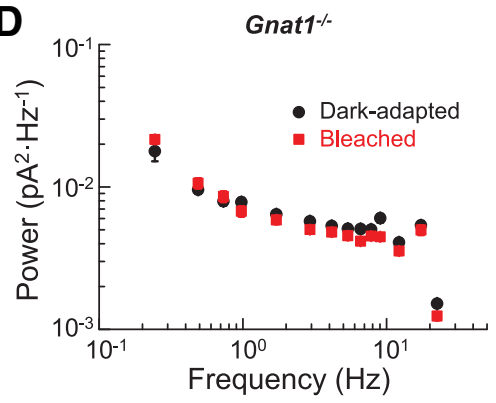

Figure 4. Bleach-induced discrete transduction activity in single WT rods in darkness. $A$, Current recorded in darkness from a dark-adapted unbleached WT rod (dark-adapted), a rod $2 \mathrm{~h}$ after 1.4\% rhodopsin bleach (bleached), an unbleached rod in $500 \mathrm{~nm}$ dim background light producing an estimated $0.14 \mathrm{R}^{*} \mathrm{~S}^{-1}$ (dark-adapted + dim background light), and the averaged rod instrumental noise $(n=6)$ recorded in bright background light (instrumental noise). $\boldsymbol{B}$, Averaged power spectra of the dark current recorded from WT rods that were dark-adapted (dark-adapted, black circles, $n=14$ ), after a 1.4\% rhodopsin bleach and incubation in darkness for $2 \mathrm{~h}$ (bleached, red squares, $n=16$ ), or in bright background light (instrumental noise, $n=6$ ). Dashed line is a spectrum from dark-adapted rods under dim background light $(n=4)$ as in $\boldsymbol{A}$. C, Current recorded in darkness from a dark-adapted unbleached Gnat $1^{-1-}$ rod (dark-adapted) and a Gnat ${ }^{-1-}$ rod $2 \mathrm{~h}$ after $1.4 \%$ rhodopsin bleach (bleached). D, Averaged power spectra of the dark current recorded from $\mathrm{Gnat}^{-1-}$ rods that were dark-adapted (dark-adapted, black circles, $n=10$ ) or after a $1.4 \%$ rhodopsin bleach and incubation in darkness for $2 \mathrm{~h}$ (bleached, red squares, $n=10$ ). Plots in $\boldsymbol{B}$ and $\boldsymbol{D}$ are shown as mean \pm SEM.

$(14.5 \pm 0.8 \mathrm{pA}, n=14 \mathrm{vs} 13.4 \pm 0.6 \mathrm{pA}, n=16)$, allowing us the direct comparison of their power spectra. To further demonstrate that the source of the increased activity in bleached rods is indeed opsin, we compared the power spectra of dark-adapted and bleached Gnat $1^{-1-}$ rods, in which opsin would not be expected to produce a change in transduction activity due to the lack of transducin. Just as in case of GCAP-deficient rods (Fig. $2 A, B$ ), we found that, in Gnat $^{-/-}$rods with normal GCAP expression, the level of activity detectable in their dark current (Fig. 4C) and in their power spectrum (Fig. 4D) after the bleach were comparable to those in dark-adapted rods. Therefore, in rods with normal GCAP expression, the lack of transducin blocked the increase in transduction activity after the small bleach, indicating that such activity originates upstream from transducin in the transduction cascade. Together, these data suggest that the bleach-induced increase in transduction activity is present not only in GCAP-deficient rods, but also in WT rods, that this activity is generated by opsin, and that it resembles photoresponse events.

\section{Discrete events in darkness from Rpe $65^{-/-}$rods regenerated with non-activatable rhodopsin}

Our results so far demonstrated that the introduction of a small fraction of opsin by a bleach results in the generation of photoresponse-like events. One possibility is that these events are produced directly by opsin when it shifts to an active, meta II-like state. However, rhodopsin is packed extremely tightly in the disks of the ROS (Fotiadis et al., 2003), so the few opsins introduced by the bleach are likely to be in close proximity to unbleached rhodopsin molecules. Therefore, an alternative to opsin directly activating the transduction cascade is that it somehow promotes the thermal activation of an adjacent rhodopsin molecule via transactivation (Neri et al., 2010; Rivero-Müller et al., 2010). To address this possibility, we used rhodopsin regenerated with the chromophore analog 11-cis-7-ring-retinal.

11-cis-7-ring-retinal is an artificially synthesized chromophore analog (Fig. $5 A$ ) that has a seven-membered ring that prevents cis-trans isomerization. Therefore, rhodopsin regenerated with this analog (11-cis-7-ring-rhodopsin) is locked in its ground state and cannot be activated. We validated the properties of 11-cis-7-ring-rhodopsin by biochemical experiments after reconstituting bovine opsin with 11-cis-7-ring-retinal. (Kuksa et al., 2002). Whereas rhodopsin regenerated with the native 11-cis-retinal chromophore was readily bleached by exposure to bright light (Fig. $5 B$, left), its 11-cis-7-ring counterpart was unbleachable and was not affected by exposure to light (Fig. $5 \mathrm{~B}$, right). Further biochemical assays demonstrated the efficient activation of G-protein transducin by rhodopsin (Fig. 5C, left) with a rate, $k=3.3 \pm 0.3 \times 10^{-3} \mathrm{~s}^{-1}$, calculated from three independent experiments. In contrast, 11-cis-7-ring-rhodopsin was unable to activate transducin (Fig. $5 C$, right), making it perfectly suitable for our goal of testing transactivation of rhodopsin by an adjacent opsin.

We used Rpe65 ${ }^{-I-}$ rods to regenerate 11-cis- or 11-cis-7-ringrhodopsin. RPE65 is the enzyme required for the production of 


\section{A}

\section{1-cis-retinal}<smiles>CC(/C=C\C=C(C)\C=C\C=O)=C\C=O</smiles>

B

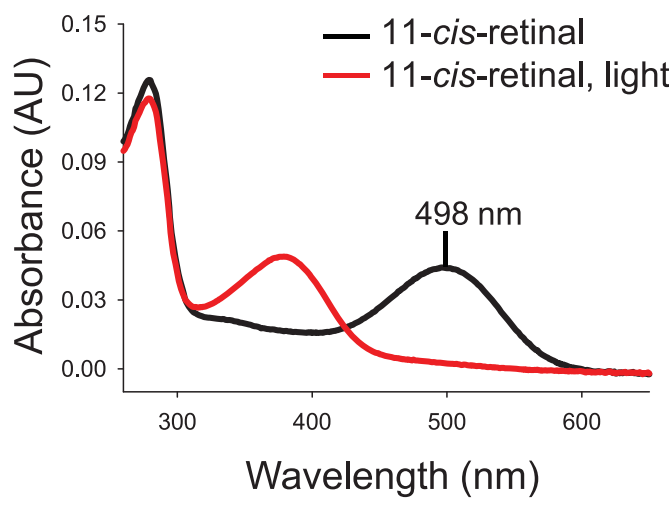

C

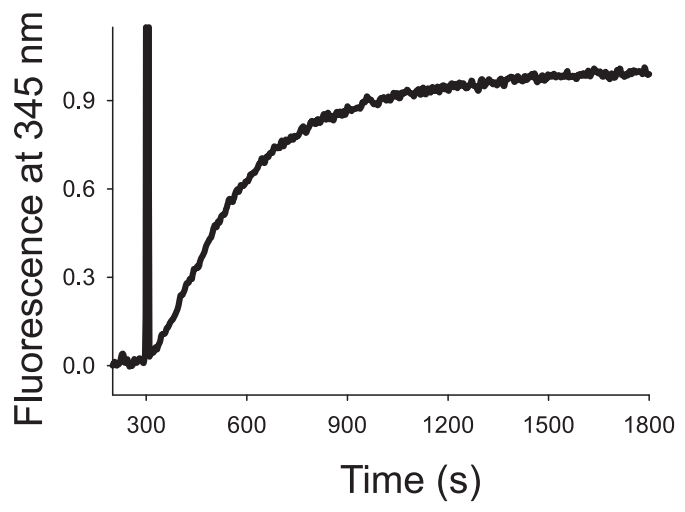

\section{1-cis-7-ring-retinal}
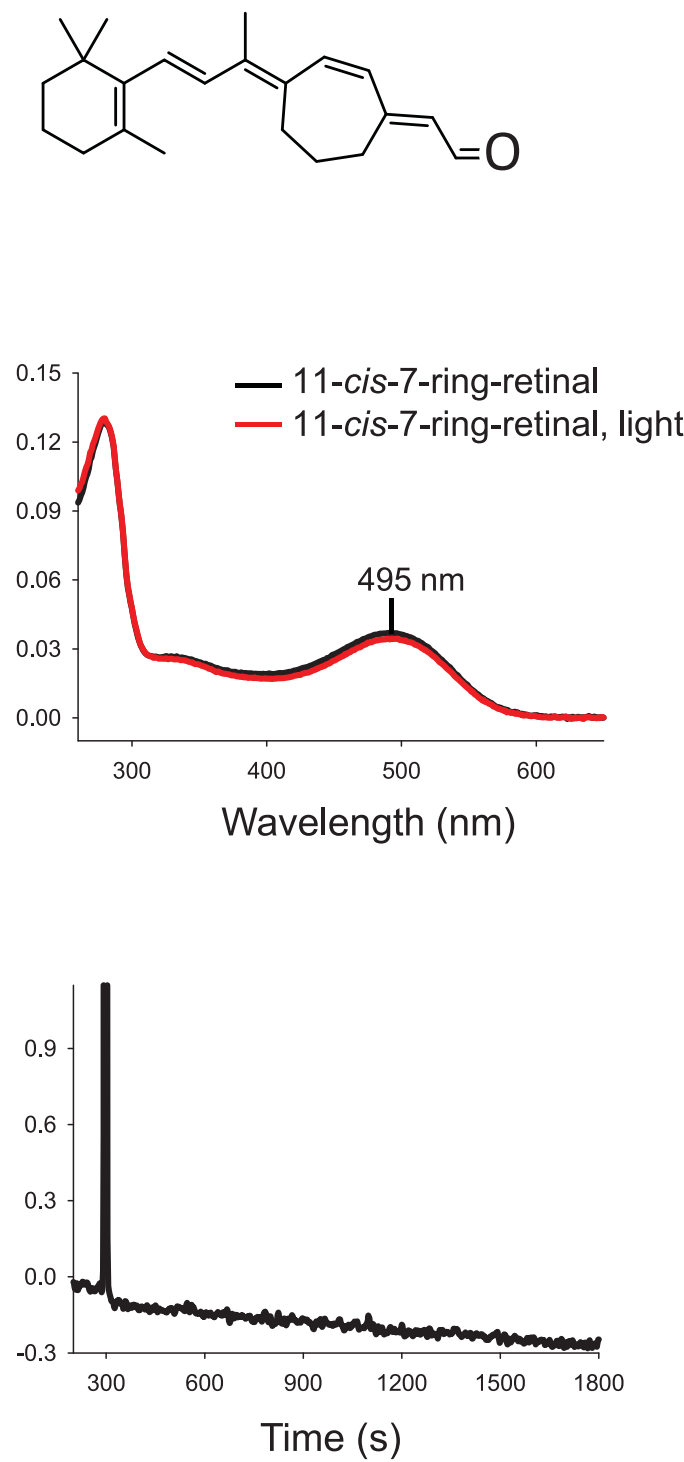

Figure 5. Spectral and functional properties of rhodopsin and 11-cis-7-ring-rhodopsin. A, Structures of 11-cis-retinal (left) and 11-cis-7-ring-retinal (right). B, UV-Vis absorption spectra of 1D4 immunoaffinity-purified rhodopsin (11-cis-retinal-bound; left) or 11-cis-7-ring-rhodopsin (right) in the dark (black) or after 5 min light illumination through a band-pass filter at 480 - $520 \mathrm{~nm}$ (red). C, Change in intrinsic fluorescence of $\alpha$-subunit of transducin due to interaction with light activated rhodopsin (left) or 11-cis-7-ring-rhodopsin (right). The transducin activation rate by rhodopsin, $k$, was calculated from three independent experiments.

11-cis-retinal chromophore in the retinal pigment epithelium (Redmond et al., 1998). Therefore, the photoreceptors in Rpe $65^{-1-}$ mice lack endogenous rhodopsin and their outer segments contain largely apo-opsin, with only a trace amount of 9-cis-retinal-bound isorhodopsin (Fan et al., 2003). Importantly, the lack of chromophore does not impair the rod phototransduction machinery because regeneration of the pigment in $R p e 65^{-1-}$ rods with exogenous 11-cis-retinal largely restores normal rod function (Van Hooser et al., 2000; Ablonczy et al., 2002; see also Figs. $6 C$ ). We first determined a regeneration protocol in Rpe $65^{-1-}$ rods in control experiments with 11-cis-retinal to establish a condition similar to the one in mildly bleached $\mathrm{Gcaps}^{-1-}$ rods. This allowed us to regenerate the bulk of rhodopsin in the Rpe $65^{-1-}$ rods while leaving a small residual fraction of free opsin. Although control vehicle-treated $R p e 65^{-1-}$ rods have a very high content of opsin, they showed no photoresponse-like discrete events because they are strongly desensitized and could not amplify the activity of opsin to detectable levels, so their dark current was dominated by instrumental noise (Fig. 6A, vehicle). Consequently, the low-frequency component of their power spectrum was suppressed (Fig. 6B). As shown previously (Fan et al., 2005), vehicle-treated Rpe65 $5^{-1-}$ rods were highly desensitized (Fig. 6C, black circles). The residual photoresponses in these rods originated from the small fraction of endogenous isorhodopsin (Fan et al., 2003). After incubating Rpe65 ${ }^{-1-}$ rods with $100 \mu \mathrm{M} 11$-cis-retinal for $3 \mathrm{~h}$, we found that flash sensitivity was increased to nearly the level of dark-adapted WT rods (Fig. 6C, red squares), indicating almost complete regeneration of rho- 
A

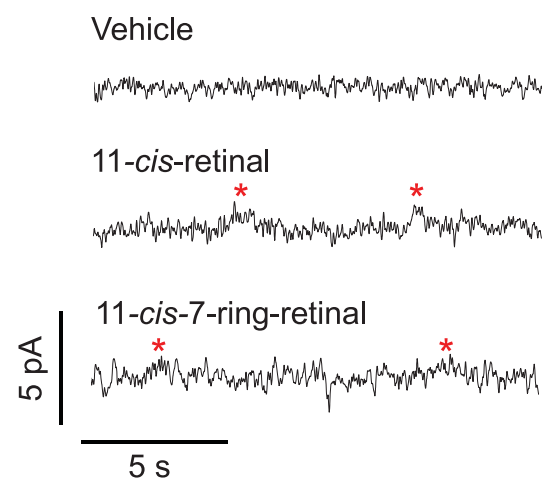

B

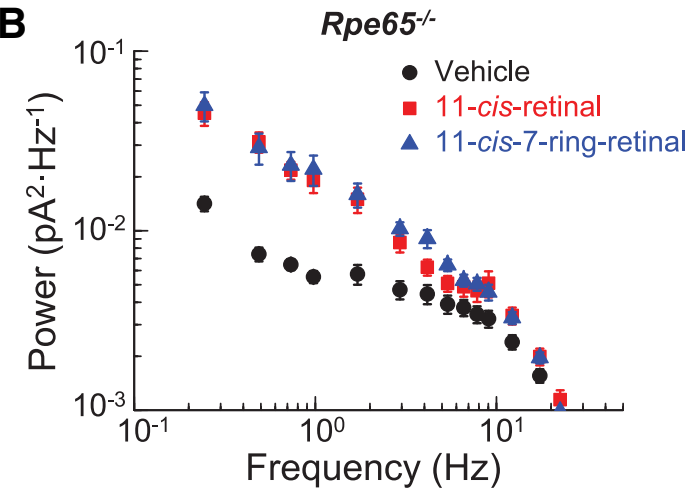

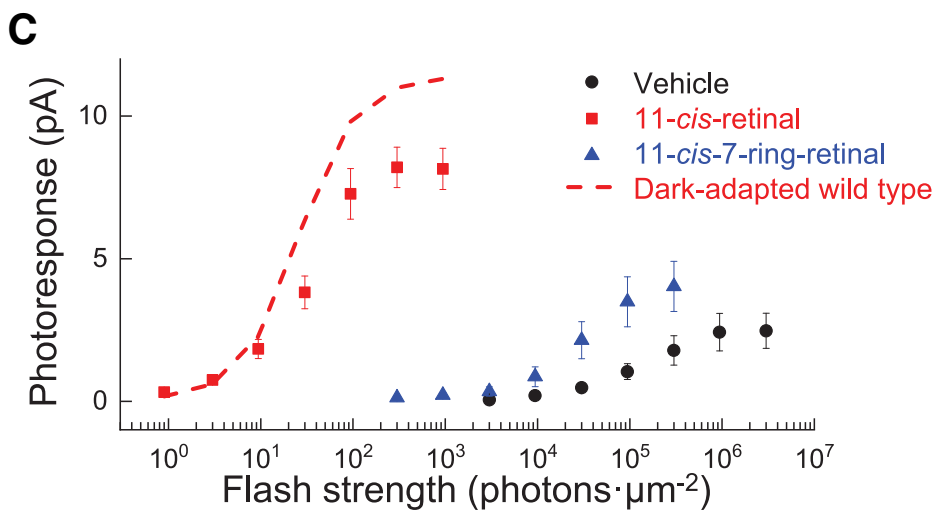

Figure 6. Transduction activity in Rpe65 $5^{-1-}$ rods after pigment regeneration. $A$, Current recorded from Rpe65 $5^{-1-}$ rods incubated in darkness for $3 \mathrm{~h}$ with vehicle for control (vehicle), $100 \mu \mathrm{M}$ exogenous 11-cis-retinal (11-cis-retinal), or 11-cis-7-ring-retinal (11-cis-7-ring-retinal) for pigment regeneration. Asterisks denote discrete photoresponse-like events. $\boldsymbol{B}$, Averaged power spectra of the dark current recorded from rods incubated in darkness for $3 \mathrm{~h}$ with vehicle (vehicle, black circles, $n=8$ ), $100 \mu \mathrm{m}$ exogenous 11 -cis-retinal (11-cis-retinal, red squares, $n=9$ ), or $100 \mu \mathrm{m}$ 11-cis-7-ring-retinal (11-cis-7-ring-retinal, blue triangles, $n=14$ ). C, Averaged intensity-response relations of rods incubated in darkness for $3 \mathrm{~h}$ with vehicle (vehicle, black circles, $n=8$ ), $100 \mu \mathrm{m}$ exogenous 11-cis-retinal (11-cis-retinal, red squares, $n=8$ ), or $100 \mu \mathrm{m}$ 11-cis-7-ring-retinal (11-cis-7-ring-retinal, blue triangles, $n=8$ ). Responses were obtained by 2 or 20 ms of calibrated flash stimulation from a $505 \mathrm{~nm}$ LED. The red dash line is an averaged intensity-response relation of dark-adapted WT rods $(n=4)$ for comparison. Plots in $\boldsymbol{B}$ and $\boldsymbol{C}$ are shown as mean \pm SEM.

dopsin. At the same time, apparent photoresponse-like events could now be observed frequently (Fig. 6A, asterisks in 11-cisretinal trace). This result is consistent with our small bleach studies with Gcaps $^{-1-}$ and WT rods described above and indicates that the small residual fraction of free, un-regenerated opsin in the 11-cis-retinal-treated Rpe $65^{-1-}$ rods was able to generate discrete photoresponse-like events. Although the amplitude of these events was small, making them barely detectable in $R p e 65^{-1-}$ rods, the large increase in low-frequency (discrete) activity in 11-cis-retinal-treated rods compared with vehicle-treated controls was clearly observed in their respective power spectra (Fig. 6B).

Finally, we applied 11-cis-7-ring-retinal to Rpe65 ${ }^{-1-}$ rods using the regeneration protocol determined above. Regeneration of rhodopsin with 11-cis-7-ring-retinal would be expected to relieve the bleaching adaptation in rods by removing most of the free opsin, thus restoring the high dark-adapted phototransduction amplification. Indeed, treatment with 11-cis-7-ring-retinal resulted in a partial recovery of sensitivity in $R p e 65^{-1-}$ rods (Fig. $6 C)$. Therefore, as expected, regeneration of opsin with 11-cis-7ring-retinal quenched opsin and relieved bleaching adaptation. However, these cells were still three orders of magnitude less sensitive that their counterparts treated with 11-cis-retinal. This finding supports our biochemical results (Fig. 5) and is consistent with the notion that 11-cis-7-ring-retinal rhodopsin is nonactivatable and does not increase the quantum catch of the rods. Therefore, any photoactivation in the $R$ pe $65^{-1-}$ rods treated with 11-cis-7-ring-retinal would still be driven by the same trace amount of endogenous isorhodopsin as in the control vehicletreated $R p e 65^{-1-}$ rods, resulting in identical effective quantum catch of rods in the two conditions. Despite the inability of 11cis-7-ring-retinal rhodopsin to activate the rod transduction cascade, we observed discrete events in Rpe $65^{-1-}$ rods treated with 11-cis-7-ring-retinal (Fig. 6A, asterisks in 11-cis-7-ring-retinal trace). In addition, the power spectra of rods exposed to 11-cisretinal and these treated with 11-cis-7-ring-retinal were essentially identical (Fig. 6B). Therefore, the level of light-independent transduction activity for rods containing a small amount of opsin and normal rhodopsin (with 11-cis-retinal) versus non-activatable rhodopsin (with 11-cis-7-ring-retinal) were comparable. Due to its inability to be activated, rhodopsin regenerated with 11-cis-7-ring-retinal could be ruled out as the source of discrete photoresponse-like events due to transactivation by adjacent opsin. We conclude that these events were generated directly by opsin, which should be able to activate the phototransduction cascade and produce responses similar to those generated by photoactivated rhodopsin.

Treatment with 11-cis-retinal quenches the discrete activity in dark-adapted Gcaps ${ }^{-/-}$rods

Our finding that free opsin produces photoresponse-like events in darkness brought into question the origin of discrete thermal events in dark-adapted rods. Previously, these events had been 
attributed exclusively to spontaneous, thermal activation of rhodopsin (Yau et al., 1979; Burns et al., 2002; Yanagawa et al., 2015). Our recordings were done at the same temperature and always from adult rods with presumably comparable rod outer segments and total number of rhodopsin molecules contained within them. Therefore, it would be expected that they would also display a comparable frequency of discrete events caused by spontaneous thermal activation of rhodopsin. However, we observed a substantial, nearly 50-fold variability in the rate of discrete events observed across darkadapted unbleached rods, from a high of $0.0839 \mathrm{~s}^{-1}$ to as low as $0.0018 \mathrm{~s}^{-1}$. Overall, from $5887 \mathrm{~s}$ or recordings from 23 rods, we observed 31 bumps that were within $30 \%$ of the size of the estimated single photon response, giving an average rate of $0.0058 \mathrm{~s}^{-1}$. In contrast, we observed only 12 bumps from 4063 s total recording time from 18 dark-adapted rods that were treated with exogenous 11cis-retinal to remove residual free opsin. The corresponding rate of $0.0030 \mathrm{~s}^{-1}$ was notably lower than in untreated darkadapted rods. Together, these findings suggest that a non-negligible fraction of the discrete events observed in darkadapted mouse rods could have been generated not by thermal activation of rhodopsin, but rather by conversion of residual free opsin from its inactive to its active state. This notion is consistent with a recent study suggesting that 11-cisretinal can be released from rhodopsin reversibly and without photoactivation, resulting in as many as $\sim 10^{4}-10^{5}$ free opsin molecules in dark-adapted rods (Tian et al., 2017; see also Defoe and Bok, 1983). The rate of discrete events in our quietest rods that were treated with exogenous chromophore to remove residual opsin was $\sim 0.0012 \mathrm{~s}^{-1}$. Because the bulk of the free opsin in these rods would have been converted into rhodopsin by recombining with 11-cis-retinal, these events likely reflect almost exclusively thermal activation of rhodopsin, suggesting that its stability could be as much as 10-fold higher than previously estimated (Mendez et al., 2001).

\section{Discussion}

Our results demonstrate the appearance of discrete protoresponse-like events after very mild bleaches in mouse rod photoreceptors. Several independent lines of evidence suggest that, surprisingly, these events are generated by activation of the rod transduction cascade by single opsin molecules. First, we show that these events persist for up to $12 \mathrm{~h}$ after the bleach. Reversal of metarhodopsin intermediates back to the physiologically active meta II
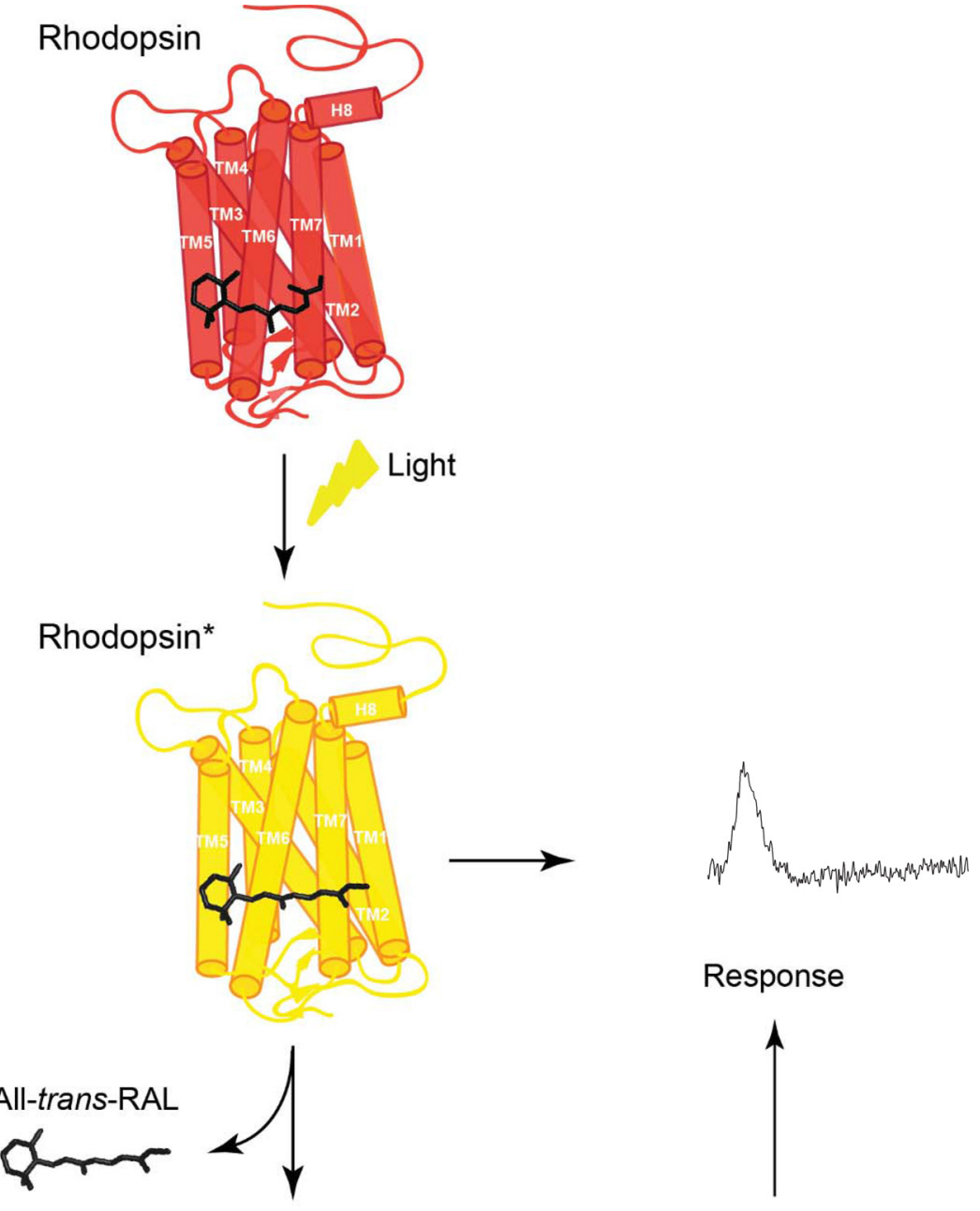

Response
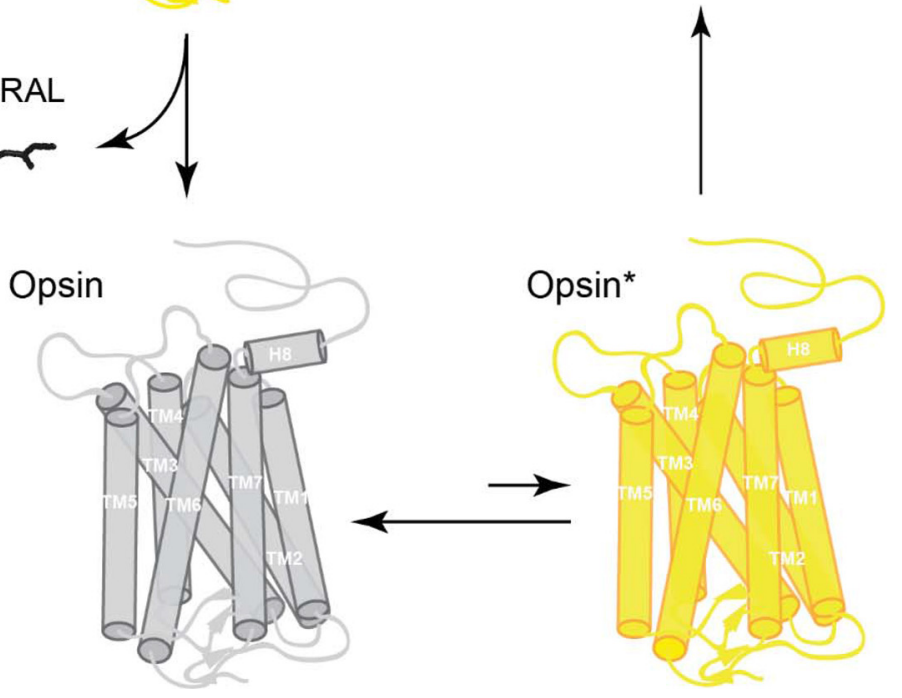

Figure 7. Model of the mechanism of activation of rod phototransduction by free opsin. The chromophore 11-cis-retinal binds to apoprotein opsin via a protonated Schiff base in the retinal binding pocket forming the visual pigment (rhodopsin). Exposure of rhodopsin to light illumination results in the isomerization of 11-cis-retinal to all-trans-retinal, followed by conformational changes within protein, leading to formation of the receptor photoactivated state (rhodopsin*). Eventually, all-trans-retinal chromophore dissociates from the binding pocket of the short-lived rhodopsin*, resulting in the formation of unliganded opsin and free all-trans-retinal. Such ligand-free opsin exists in equilibrium between a predominant inactive opsin (opsin) and rare active opsin (opsin*). Both photoactivated rhodopsin* and opsin* generate a cellular response that can be recorded. has been shown in the past to produce discrete events in the first few minutes after a small bleach in toad rods (Leibrock et al., 1994; Leibrock and Lamb, 1997). We observed a similar large increase in discrete transduction activity in the first few postbleach minutes in mouse rods. However, contributions from metarhodopsin intermediates would be expected to become negligible upon their decay several hours after the bleach. Indeed, we found that the initial high frequency of discrete events gradually 
declined with a time course consistent with the gradual decay of photoactivated rhodopsins to free opsin and all-trans-retinal (Imai et al., 2007; Nymark et al., 2012). The residual elevated discrete transduction activity persisted for up to $12 \mathrm{~h}$ after the bleach, ruling out metarhodopsin intermediates as its origin. Therefore, although both mechanisms are likely to produce discrete events in bleached rods, metarhodopsin would be dominating in the first few minutes after the bleach, whereas opsin would be the exclusive source for discrete events at later times. Second, we show that the bleach-induced increase in transduction activity is readily reversed when bleached rods are treated with exogenous 11-cis-retinal. Such a treatment would convert the opsin created by the bleach back to the ground state inactive rhodopsin. Therefore, the discrete protoresponse-like events are associated with the presence of opsin. Third, we show that discrete activity is present in Rpe65 ${ }^{-1-}$ rods after the bulk of their opsin has been regenerated to rhodopsin, leaving only a trace amount of free opsin in these rods. This result rules out the possibility that the discrete events are caused by reversible binding of bleachproduced all-trans-retinal to opsin (Buczyłko et al., 1996; Kefalov et al., 1999; Schafer et al., 2016) because this retinoid is not present in Rpe $65^{-1-}$ rods. Fourth, we show that discrete activity is present in rods where rhodopsin is locked in an inactive state by 11-cis-7-ring-retinal. This result rules out the possibility that the discrete events are a result of rhodopsin activation, either directly or by an adjacent opsin molecule. Fifth, we show that the bleachinduced increase in discrete events is blocked by the deletion of transducin in both GCAP-deficient and GCAP-proficient rods. Because transduction activity caused by spontaneous activation of individual transducins is unlikely to produce discrete events of sizeable amplitude, the only possible source for the discrete events that remains is free opsin. Sixth, we observed a nearly 50 -fold variability in the rate of discrete events observed across dark-adapted unbleached rods. Because rhodopsin thermal activation would be expected to produce consistent and reproducible rate of discrete events across rods, the large variability of the rate of discrete events in unbleached dark-adapted rods suggests that a substantial fraction of these discrete events is generated by an alternative mechanism different from thermal activation of rhodopsin. Conversely, a variable amount of free opsin can easily explain the variable rate of discrete events in unbleached rods. Finally, seventh, we observed a twofold reduction in the rate of discrete events in dark-adapted rods after treating them with exogenous 11-cis-retinal. Such a treatment would convert any residual apo-opsin in these rods to rhodopsin, effectively quenching the activity produced by opsin. The twofold reduction in discrete events caused by this manipulation is inconsistent with thermal activation of rhodopsin as its sole source and suggests that a substantial fraction of the discrete events observed in dark-adapted rods are generated by opsin. Together, these results clearly demonstrate that free opsin can activate the rod transduction cascade to produce detectable photoresponse-like events.

The role of free opsin in bleaching adaptation has been established with both biochemical and electrophysiological studies. However, the state of opsin that mediates the constitutive activity observed in photoreceptors following a bleach has remained unclear. The latest estimates indicate that meta II is inactivated with a time constant of $40 \mathrm{~ms}$ (Gross and Burns, 2010) and activates only $\sim 20$ transducin molecules during its lifetime (Leskov et al., 2000). The effective activation of the transduction cascade by opsin in mouse rods is estimated to be five orders of magnitude smaller than that of photoactivated rhodopsin (Fan et al., 2005). Therefore, the alternative mechanism of opsin activity, a large number of very small amplitude events, would be expected to activate only 0.0005 transducins on average. However, such a scenario will not produce discrete events and current noise as the ones consistently seen in our recordings from bleached rods. Instead, a high frequency of small-amplitude events will average over time to produce a visibly smooth trace, similar to the continuous noise observed in dark-adapted rods (Rieke and Baylor, 1996). Therefore, the only mechanism that can explain the large fluctuations in the dark current of bleached rods observed by us is the occurrence of large events at a low frequency, similar to what is observed when a dim background produces 1-2 pigment activations/s. We conclude that opsin exists in equilibrium between a heavily favored inactive state and a rare meta II-like active state (Fig. 7). A recent study comparing the structural kinetics of rhodopsin and opsin supports our interpretation (Kawamura et al., 2013). The similarity between the meta II- and opsin-driven responses suggests that the active meta II-like conformation of opsin is maintained long enough to sequentially activate a number of transducins comparable to that activated by a single meta II. Therefore, it would be important to determine whether, similar to meta II (Makino et al., 2003), the timely inactivation of opsin requires phosphorylation and the binding of arrestin.

Bleaching adaptation has been investigated by electrophysiological means for decades. So why have discrete events produced by single opsin molecules not been observed until now? One reason is the prevalent use of bright $(>90 \%)$ bleaches in past studies. As our data show, when the bleach fraction increases beyond $\sim 5 \%$, the frequency of the opsin-driven discrete events becomes so high that observation of individual events becomes impossible. In addition, the higher cumulative activity of opsin in brighter bleaches is sufficient to induce bleaching adaptation in the rods, reducing the gain of the transduction cascade and making individual discrete events too small to be observed. The combination of two critical experimental approaches allowed us to overcome these issues. First, we used small bleaches $(\sim 1 \%)$ such that rods were not desensitized by bleaching adaptation, so the amplitude of discrete events was not reduced. In addition, the frequency of the opsin-driven discrete events was still relatively low so that fluctuations in the dark current caused by these events could be observed above the noise in our recordings. Second, we used GCAP-deficient rods, which amplified the discrete events by several fold, greatly facilitating their observation. Importantly, even though such discrete events were difficult to discern in WT rods, power spectral analysis clearly demonstrated their presence after mild bleaches. Considering recent evidence that small amounts of free opsin comparable to our $1 \%$ bleaches could be present even in dark-adapted rods (Tian et al., 2017), photoresponse-like transduction activity driven by opsin is likely to contribute to the basal transduction activity in darkness and in dim light conditions.

Rhodopsin is a member of a large family of homologous receptors called GPCRs (Palczewski, 2006). These receptors exist in a myriad of conformations with different activity, which is modulated by the binding of a ligand. When the ligand binds to the receptor, it selectively stabilizes it in a fully active, partially active, or inactive conformation (Salon et al., 2011). Similarly, Gproteins can selectively and productively bind to one of these conformations and initiate signaling cascades (Hilger et al., 2018). Therefore, GPCRs display some level of constitutive activity even without ligands. Opsin is no exception and, as our data here indicate, it can achieve high activity even without its ligand, which in this case is covalently attached chromophore. Opsin can assume the fully active conformation at low $\mathrm{pH}$ (Vogel and Siebert, 2001; Choe et al., 2011), implying that it does exist in a 
thermodynamic equilibrium between different protonated/activity states. Our electrophysiological recordings presented here demonstrate the presence of such a high-activity opsin state in intact rod photoreceptors. Future structural studies might be able to determine whether, similar to photoactivated rhodopsin and many other proteins (Van Eps et al., 2017), opsin also can exist in a manifold of active conformational substates.

Finally, our findings bring new questions about the mechanisms that produce the substantial light-independent transduction activity in cones. The visual pigments in cones are substantially less stable than those in rods. Therefore, thermal activation of cone visual pigments has been estimated to occur 10,000-fold more frequently than that of rod pigments (Kefalov et al., 2003). In addition, whereas a covalent bond between opsin and 11-cis-retinal is rather stable in rod visual pigments, the chromophore is readily released from cone pigments (Matsumoto et al., 1975; Kefalov et al., 2005), so a substantial amount of free opsin is present even in dark-adapted cones, at least in the case of amphibians. Future structural and functional studies will determine whether cone opsins are mechanistically similar to rod opsins.

\section{References}

Ablonczy Z, Crouch RK, Goletz PW, Redmond TM, Knapp DR, Ma JX, Rohrer B (2002) 11-cis-retinal reduces constitutive opsin phosphorylation and improves quantum catch in retinoid-deficient mouse rod photoreceptors. J Biol Chem 277:40491-40498. CrossRef Medline

Baylor DA, Lamb TD, Yau KW (1979) Responses of retinal rods to single photons. J Physiol 288:613-634. Medline

Buczyłko J, Saari JC, Crouch RK, Palczewski K (1996) Mechanisms of opsin activation. J Biol Chem 271:20621-20630. CrossRef Medline

Burns ME, Mendez A, Chen J, Baylor DA (2002) Dynamics of cyclic GMP synthesis in retinal rods. Neuron 36:81-91. CrossRef Medline

Calvert PD, Krasnoperova NV, Lyubarsky AL, Isayama T, Nicoló M, Kosaras B, Wong G, Gannon KS, Margolskee RF, Sidman RL, Pugh EN Jr, Makino CL, Lem J (2000) Phototransduction in transgenic mice after targeted deletion of the rod transducin alpha-subunit. Proc Natl Acad Sci U S A 97:13913-13918. CrossRef Medline

Campbell FW, Rushton WA (1955) Measurement of the scotopic pigment in the living human eye. J Physiol 130:131-147. CrossRef Medline

Choe HW, Kim YJ, Park JH, Morizumi T, Pai EF, Krauss N, Hofmann KP, Scheerer P, Ernst OP (2011) Crystal structure of metarhodopsin II. Nature 471:651-655. CrossRef Medline

Cornwall MC, Fein A, MacNichol EF Jr (1990) Cellular mechanisms that underlie bleaching and background adaptation. J Gen Physiol 96:345372. CrossRef Medline

Cornwall MC, Matthews HR, Crouch RK, Fain GL (1995) Bleached pigment activates transduction in salamander cones. J Gen Physiol 106:543557. CrossRef Medline

Cornwall MC, Fain GL (1994) Bleached pigment activates transduction in isolated rods of the salamander retina. J Physiol 480:261-279. CrossRef Medline

Defoe DM, Bok D (1983) Rhodopsin chromophore exchanges among opsin molecules in the dark. Invest Ophthalmol Vis Sci 24:1211-1226. Medline

Ernst OP, Lodowski DT, Elstner M, Hegemann P, Brown LS, Kandori H (2014) Microbial and animal rhodopsins: structures, functions, and molecular mechanisms. Chem Rev 114:126-163. CrossRef Medline

Fahmy K, Sakmar TP (1993) Regulation of the rhodopsin-transducin interaction by a highly conserved carboxylic acid group. Biochemistry 32 : 7229-7236. CrossRef Medline

Fain GL, Matthews HR, Cornwall MC (1996) Dark adaptation in vertebrate photoreceptors. Trends Neurosci 19:502-507. CrossRef Medline

Fain GL, Matthews HR, Cornwall MC, Koutalos Y (2001) Adaptation in vertebrate photoreceptors. Physiol Rev 81:117-151. CrossRef Medline

Fan J, Rohrer B, Moiseyev G, Ma JX, Crouch RK (2003) Isorhodopsin rather than rhodopsin mediates rod function in RPE65 knock-out mice. Proc Natl Acad Sci U S A 100:13662-13667. CrossRef Medline

Fan J, Woodruff ML, Cilluffo MC, Crouch RK, Fain GL (2005) Opsin activation of transduction in the rods of dark-reared Rpe65 knockout mice. J Physiol 568:83-95. CrossRef Medline
Farrens DL, Altenbach C, Yang K, Hubbell WL, Khorana HG (1996) Requirement of rigid-body motion of transmembrane helices for light activation of rhodopsin. Science 274:768-770. CrossRef Medline

Fotiadis D, Liang Y, Filipek S, Saperstein DA, Engel A, Palczewski K (2003) Atomic-force microscopy: rhodopsin dimers in native disc membranes. Nature 421:127-128. CrossRef Medline

Goc A, Angel TE, Jastrzebska B, Wang B, Wintrode PL, Palczewski K (2008) Different properties of the native and reconstituted heterotrimeric $G$ protein transducin. Biochemistry 47:12409-12419. CrossRef Medline

Gross OP, Burns ME (2010) Control of rhodopsin's active lifetime by arrestin-1 expression in mammalian rods. J Neurosci 30:3450-3457. CrossRef Medline

Heck M, Hofmann KP (2001) Maximal rate and nucleotide dependence of rhodopsin-catalyzed transducin activation: initial rate analysis based on a double displacement mechanism. J Biol Chem 276:10000-10009. CrossRef Medline

Hilger D, Masureel M, Kobilka BK (2018) Structure and dynamics of GPCR signaling complexes. Nat Struct Mol Biol 25:4-12. CrossRef Medline

Imai H, Kefalov V, Sakurai K, Chisaka O, Ueda Y, Onishi A, Morizumi T, Fu Y, Ichikawa K, Nakatani K, Honda Y, Chen J, Yau KW, Shichida Y (2007) Molecular properties of rhodopsin and rod function. J Biol Chem 282: 6677-6684. CrossRef Medline

Jäger S, Palczewski K, Hofmann KP (1996) Opsin/all-trans-retinal complex activates transducin by different mechanisms than photolyzed rhodopsin. Biochemistry 35:2901-2908. CrossRef Medline

Jastrzebska B (2015) Oligomeric state of rhodopsin within rhodopsintransducin complex probed with succinylated concanavalin A. Methods Mol Biol 1271:221-233. CrossRef Medline

Jastrzebska B, Salom D, Jin H, Cao P, Sun W, Palczewski K, Feng Z (2013) Expression of mammalian $\mathrm{G}$ protein-coupled receptors in caenorhabditis elegans. Methods Enzymol 520:239-256. CrossRef Medline

Jones GJ, Fein A, MacNichol EF Jr, Cornwall MC (1993) Visual pigment bleaching in isolated salamander retinal cones: microspectrophotometry and light adaptation. J Gen Physiol 102:483-502. CrossRef Medline

Jones GJ (1998) Membrane current noise in dark-adapted and lightadapted isolated retinal rods of the larval tiger salamander. J Physiol 511: 903-913. CrossRef Medline

Kawamura S, Gerstung M, Colozo AT, Helenius J, Maeda A, Beerenwinkel N, Park PS, Müller DJ (2013) Kinetic, energetic, and mechanical differences between dark-state rhodopsin and opsin. Structure 21:426-437. CrossRef Medline

Kefalov V, Fu Y, Marsh-Armstrong N, Yau KW (2003) Role of visual pigment properties in rod and cone phototransduction. Nature 425:526531. CrossRef Medline

Kefalov VJ, Estevez ME, Kono M, Goletz PW, Crouch RK, Cornwall MC, Yau KW (2005) Breaking the covalent bond-a pigment property that contributes to desensitization in cones. Neuron 46:879-890. CrossRef Medline

Kefalov VJ, Carter Cornwall M, Crouch RK (1999) Occupancy of the chromophore binding site of opsin activates visual transduction in rod photoreceptors. J Gen Physiol 113:491-503. CrossRef Medline

Kuksa V, Bartl F, Maeda T, Jang GF, Ritter E, Heck M, Preston Van Hooser J, Liang Y, Filipek S, Gelb MH, Hofmann KP, Palczewski K (2002) Biochemical and physiological properties of rhodopsin regenerated with 11cis-6-ring- and 7-ring-retinals. J Biol Chem 277:42315-42324. CrossRef Medline

Leibrock CS, Reuter T, Lamb TD (1994) Dark adaptation of toad rod photoreceptors following small bleaches. Vision Res 34:2787-2800. CrossRef Medline

Leibrock CS, Lamb TD (1997) Effect of hydroxylamine on photon-like events during dark adaptation in toad rod photoreceptors. J Physiol 501: 97-109. CrossRef Medline

Leskov IB, Klenchin VA, Handy JW, Whitlock GG, Govardovskii VI, Bownds MD, Lamb TD, Pugh EN Jr, Arshavsky VY (2000) The gain of rod phototransduction: reconciliation of biochemical and electrophysiological measurements. Neuron 27:525-537. CrossRef Medline

Lyubarsky AL, Daniele LL, Pugh EN Jr (2004) From candelas to photoisomerizations in the mouse eye by rhodopsin bleaching in situ and the light-rearing dependence of the major components of the mouse ERG. Vision Res 44:3235-3251. CrossRef Medline

Lyubarsky AL, Pugh EN Jr (2007) Over 98\% of 11-cis retinal in the dark- 
adapted mouse eye is bound to rod and cone opsins. Invest Ophthalmol Vis Sci 48:3246.

Makino CL, Wen XH, Lem J (2003) Piecing together the timetable for visual transduction with transgenic animals. Curr Opin Neurobiol 13:404-412. CrossRef Medline

Matsumoto H, Tokunaga F, Yoshizawa T (1975) Accessibility of the iodopsin chromophore. Biochim Biophys Acta 404:300-308. CrossRef Medline

Melia TJ Jr, Cowan CW, Angleson JK, Wensel TG (1997) A comparison of the efficiency of $\mathrm{G}$ protein activation by ligand-free and light-activated forms of rhodopsin. Biophys J 73:3182-3191. CrossRef Medline

Mendez A, Burns ME, Roca A, Lem J, Wu LW, Simon MI, Baylor DA, Chen J (2000) Rapid and reproducible deactivation of rhodopsin requires multiple phosphorylation sites. Neuron 28:153-164. CrossRef Medline

Mendez A, Burns ME, Sokal I, Dizhoor AM, Baehr W, Palczewski K, Baylor DA, Chen J (2001) Role of guanylate cyclase-activating proteins (GCAPs) in setting the flash sensitivity of rod photoreceptors. Proc Natl Acad Sci U S A 98:9948-9953. CrossRef Medline

Neri M, Vanni S, Tavernelli I, Rothlisberger U (2010) Role of aggregation in rhodopsin signal transduction. Biochemistry 49:4827-4832. CrossRef Medline

Nickell S, Park PS, Baumeister W, Palczewski K (2007) Three-dimensional architecture of murine rod outer segments determined by cryoelectron tomography. J Cell Biol 177:917-925. CrossRef Medline

Nymark S, Frederiksen R, Woodruff ML, Cornwall MC, Fain GL (2012) Bleaching of mouse rods: microspectrophotometry and suction-electrode recording. J Physiol 590:2353-2364. CrossRef Medline

Okada D, Nakai T, Ikai A (1989) Transducin activation by molecular species of rhodopsin other than metarhodopsin II. Photochem Photobiol 49: 197-203. CrossRef Medline

Palczewski K (2006) G protein-coupled receptor rhodopsin. Annu Rev Biochem 75:743-767. CrossRef Medline

Papermaster DS (1982) Preparation of retinal rod outer segments. Methods Enzymol 81:48-52. CrossRef Medline

Redmond TM, Yu S, Lee E, Bok D, Hamasaki D, Chen N, Goletz P, Ma JX, Crouch RK, Pfeifer K (1998) Rpe65 is necessary for production of 11cis-vitamin A in the retinal visual cycle. Nat Genet 20:344-351. CrossRef Medline

Rieke F, Baylor DA (1996) Molecular origin of continuous dark noise in rod photoreceptors. Biophys J 71:2553-2572. CrossRef Medline

Rivero-Müller A, Chou YY, Ji I, Lajic S, Hanyaloglu AC, Jonas K, Rahman N, Ji TH, Huhtaniemi I (2010) Rescue of defective G protein-coupled receptor function in vivo by intermolecular cooperation. Proc Natl Acad Sci U S A 107:2319-2324. CrossRef Medline

Saari JC (2012) Vitamin A metabolism in rod and cone visual cycles. Annu Rev Nutr 32:125-145. CrossRef Medline

Salom D, Le Trong I, Pohl E, Ballesteros JA, Stenkamp RE, Palczewski K, Lodowski DT (2006) Improvements in G protein-coupled receptor purification yield light stable rhodopsin crystals. J Struct Biol 156:497-504. CrossRef Medline
Salon JA, Lodowski DT, Palczewski K (2011) The significance of G proteincoupled receptor crystallography for drug discovery. Pharmacol Rev 63: 901-937. CrossRef Medline

Schafer CT, Fay JF, Janz JM, Farrens DL (2016) Decay of an active GPCR: conformational dynamics govern agonist rebinding and persistence of an active, yet empty, receptor state. Proc Natl Acad Sci U S A 113:1196111966. CrossRef Medline

Sommer ME, Hofmann KP, Heck M (2011) Arrestin-rhodopsin binding stoichiometry in isolated rod outer segment membranes depends on the percentage of activated receptors. J Biol Chem 286:7359-7369. CrossRef Medline

Surya A, Foster KW, Knox BE (1995) Transducin activation by the bovine opsin apoprotein. J Biol Chem 270:5024-5031. CrossRef Medline

Tian H, Sakmar TP, Huber T (2017) The energetics of chromophore binding in the visual photoreceptor rhodopsin. Biophys J 113:60-72. CrossRef Medline

Van Eps N, Caro LN, Morizumi T, Kusnetzow AK, Szczepek M, Hofmann KP, Bayburt TH, Sligar SG, Ernst OP, Hubbell WL (2017) Conformational equilibria of light-activated rhodopsin in nanodiscs. Proc Natl Acad Sci U S A 114:E3268-E3275. CrossRef Medline

Van Hooser JP, Aleman TS, He YG, Cideciyan AV, Kuksa V, Pittler SJ, Stone EM, Jacobson SG, Palczewski K (2000) Rapid restoration of visual pigment and function with oral retinoid in a mouse model of childhood blindness. Proc Natl Acad Sci U S A 97:8623-8628. CrossRef Medline

Vogel R, Siebert F (2001) Conformations of the active and inactive states of opsin. J Biol Chem 276:38487-38493. CrossRef Medline

Vu TQ, McCarthy ST, Owen WG (1997) Linear transduction of natural stimuli by dark-adapted and light-adapted rods of the salamander, Ambystoma tigrinum. J Physiol 505:193-204. CrossRef Medline

Wald G, Brown PK (1953) The molar extinction of rhodopsin. J Gen Physiol 37:189-200. CrossRef Medline

Wang JS, Nymark S, Frederiksen R, Estevez ME, Shen SQ, Corbo JC, Cornwall MC, Kefalov VJ (2014) Chromophore supply rate-limits mammalian photoreceptor dark adaptation. J Neurosci 34:11212-11221. CrossRef Medline

Woodruff ML, Lem J, Fain GL (2004) Early receptor current of wild-type and transducin knockout mice: photosensitivity and light-induced $\mathrm{Ca} 2+$ release. J Physiol 557:821-828. CrossRef Medline

Yanagawa M, Kojima K, Yamashita T, Imamoto Y, Matsuyama T, Nakanishi K, Yamano Y, Wada A, Sako Y, Schichida Y (2015) Origin of the low thermal isomerization rate of rhodopsin chromophore. Sci Rep 5:11081. CrossRef Medline

Yau KW, Matthews G, Baylor DA (1979) Thermal activation of the visual transduction mechanism in retinal rods. Nature 279:806-807. CrossRef Medline

Zimmermann K, Ritter E, Bartl FJ, Hofmann KP, Heck M (2004) Interaction with transducin depletes metarhodopsin III: a regulated retinal storage in visual signal transduction? J Biol Chem 279:48112-48119. CrossRef Medline 